\title{
Artículo de Revisión: La calidad espermática en peces y los métodos de evaluación
}

\section{Review article: Fish sperm quality and assessment methods}

\author{
Juan C. López-Hernández ${ }^{1}$, Adriana Osorio-Pérez ${ }^{1}$, Salvador A. Jiménez-Félix ${ }^{1}$, \\ Salomón Páramo-Delgadillo ${ }^{1}$, Gabriel Márquez-Couturier ${ }^{1}$, George S. Yasui ${ }^{2}$ y \\ Lenin Arias-Rodriguez ${ }^{1 *}$
}

\begin{abstract}
RESUMEN
El efecto antrópico, la pérdida de biodiversidad, el desplazamiento de especies, la introducción de especies exóticas y el incremento demográfico, han promovido aumentar el rendimiento de los cultivos, la recuperación de sitios impactados, la reintroducción de especies y la búsqueda de alternativas para comprender, y evaluar la reproducción de las especies ícticas nativas. En ello, el conocimiento y el empleo de los gametos de hembras y machos de los peces, para la producción masiva de larvas hacen necesario el uso de metodologías que permitan seleccionar todos aquellos reproductores que muestren cualidades genéticas y fisiológicas que den pauta a mejorar e incrementar la cantidad y la calidad de las larvas que serán empleadas para cultivo masivo, repoblación, producción de reproductores y para su empleo en experimentos de ciencia básica y aplicada. En esta revisión bibliográfica, se hace mención de las particularidades de las células espermáticas de los peces y de las alternativas metodológicas para evaluar su calidad, mediante la comprensión de la fisiología de la activación (porcentajes y tiempo de motilidad, tipo de movimiento y número de espermatozoides) y hasta el análisis estructural en el nivel extracelular e intracelular (morfología espermática, daño a la membrana, ensayo cometa, células vivas/muertas/apoptóticas, mismas que están en función de los objetivos de los programas de reproducción o experimentación). Con el desarrollo de equipos de citometría automática y de genómica unicelular, se ha logrado mayor comprensión del funcionamiento de las células espermáticas, de la expresión genética ligada a las cualidades celulares y del significado biológico.
\end{abstract}

Palabras clave: Calidad espermática, evaluación, métodos, peces, reproducción.

\begin{abstract}
Aspects such as anthropic effects, loss of biodiversity, species displacement, introduction of exotic species, and demographic growth have caused an increase in crop yield, recovery of impacted sites,

1 División Académica de Ciencias Biológicas, Universidad Juárez Autónoma de Tabasco (UJAT), Villahermosa, C. P. 86150, Tabasco, México. leninariasrodriguez@hotmail.com*

2 Universidade de São Paulo, São Paulo, Brasil.
\end{abstract}

Recibido: 13 septiembre 2017

Corregido: 23 abril 2018

Aceptado: 04 mayo 2018

DOI: http://dx.doi.org/10.15359/revmar.10-1.5

Rev. Mar. Cost. ESSN 1659-407X. Vol. 10 (1): 67-96, Enero-Junio 2018. 
reintroduction of species and the search for alternatives to understand and evaluate reproduction of native fish species. In such context, knowing and using both female and male gametes for massive larvae production creates the need to use methodologies that would allow sorting the brood stock with genetic and physiological traits that would improve the quantity and quality of larvae to be used for massive culture, restocking, breeding production, and experiments on basic and applied sciences. This bibliographic review mentions the particularities of fish sperm cells and methodological alternatives to assess their quality, by understanding activation physiology (motility percentages and time of activity, type of movement and sperm number), including the structural analysis at extracellular and intracellular levels (spermatic morphology, damage to the membrane, comet assay, live/dead/apoptotic cells, which depend on the main objectives of reproduction or experimental programs). The development of equipment to automated cytometry and unicellular genomics has allowed for a better understanding of the functioning of spermatic cells, genetic expression linked to cellular qualities and their biological implication.

Keywords: Sperm quality, assessment, methods, fish, reproduction.

\section{INTRODUCCIÓN}

Tras el curso de miles de años de evolución biológica, los peces como organismos típicamente acuáticos han desarrollado estrategias reproductivas que han favorecido la creación y el cobijo de necesidades bioquímicas y fisiológicas que los gametos necesitan para unirse y desencadenar el apropiado desarrollo del embrión (Wootton \& Smith, 2014a, b; Wootton \& Carl 2014; Mylonas et al. 2010; Schulz et al. 2010; Patzner, 2008; Schreck \& Moyle, 1990; Zohar \& Mylonas, 2001). En las formas de diferenciación gonadal reconocidas para los peces, es bien distinguido el gonocorismo o separación de sexos en hembras y machos, con capacidad gonádica individual para producir óvulos o espermatozoides respectivamente; en el hermafroditismo, las gónadas del mismo espécimen tienen capacidad para producir ambos gametos (Wootton
\& Carl, 2014; Wootton \& Smith, 2014a; Schulz et al. 2010). En los peces las estrategias reproductivas son variadas y complejas y la reproducción sexual es el modo típico y más común (Coward et al. 2002). En dicho sentido, se presentan dos tipos de reproducción, la externa que está presente en el 94\% de las especies de peces y la interna en tan solo el 6\% (Patzner, 2008) de las especies registradas. En la primera, los óvulos y los espermatozoides son liberados al medio acuático en un acto sincronizado, donde los gametos se activan por el agua y los espermatozoides fertilizan los óvulos (Dumorné et al. 2017; Mylonas et al. 2010; Zohar \& Mylonas, 2001). En la fertilización externa se requiere gran número de gametos, en ella el encuentro entre el óvulo y el espermatozoide es al azar, al ser ello también congruente con las oportunidades de fertilización y sobrevivencia de los embriones (Herráez et al. 2017; Rurangwa 
et al. 2004; Mylonas et al. 2017; Wootton \& Smith, 2014a, b). En el caso de la fertilización interna, los espermatozoides son depositados en el receptáculo espermático de la hembra, mediante un órgano accesorio denominado gonopodio que está presente en ciertas especies de la familia poeciliidae, o mixopterigios en elasmobranquios, lo que garantiza la fecundación cuando los óvulos de la hembra están maduros (Herráez et al. 2017; Rurangwa et al. 2004; Wootton \& Smith, 2014a, b). Generalmente, la fertilización interna es exclusiva de cuidado parental vivíparo, donde el embrión se desarrolla dentro de la madre y las larvas son liberadas como juveniles de nado libre, lo que no requiere de un gran número de gametos fertilizados, pues la oportunidad de fertilización y de sobrevivencia de los embriones de pasar a estado juvenil es asegurada (Herráez et al. 2017; Patzner, 2008; Rurangwa et al. 2004; Wootton \& Smith, 2014a, b). En la mayoría de peces teleósteos, como son las carpas, las mojarras, los robalos, los bagres, etc., la fertilización es externa y en otras especies interna, como es el caso del pez cebra Oryzias setnai, donde los espermatozoides se mantienen viables por largo tiempo en los espermatofitos que se atan a la piel que reviste el gonoporo de la hembra durante la copula, permitiendo así la fertilización sin copulas posteriores (Wootton \& Smith, 2014a). En ambos casos, la reproduc- ción está regulada por la vía cerebral, mediante la liberación de hormonas folículo estimulantes y luteinizantes, las cuales son clave para el control reproductivo endocrino (Wootton \& Smith, 2014b; Mylonas et al. 2017; Zohar \& Mylonas, 2001).

El ciclo reproductivo típico de un pez, se divide en dos fases principales: la proliferación, el crecimiento y la diferenciación de los gametos, constituyen la primera fase (vitelogénesis y espermatogénesis); mientras que la maduración de los óvulos, los espermatozoides y la preparación para la liberación, constituyen la segunda (espermiación y ovulación) (Patzner, 2008; Schulz et al. 2010, Zohar \& Mylonas, 2001). El control de la reproducción es un tópico importante en acuicultura y es uno de los factores limitantes del éxito reproductivo, en ello la calidad de los gametos es crucial (Zohar \& Mylonas, 2001), pues de esta dependen también los porcentajes de fertilización.

Los métodos para el control y el manejo de la reproducción en peces son muy diversos, estos incluyen, tratamiento hormonal, control de los parámetros físicos, almacenamiento de gametos, reversión sexual, manipulación del tiempo de reproducción, esterilización, y separación de reproductores, entre otros (Mylonas et al. 2017; Zohar \& Mylonas, 2001). 
El control de la función reproductiva de los peces en cautiverio por medios artificiales como son temperatura, fotoperiodo $\mathrm{y}$ tratamientos hormonales, son esenciales para la sustentabilidad de la producción acuícola comercial, pues gracias a ellos es posible que los gametos alcancen la maduración final y puedan ser recolectados o removidos directamente de las gónadas con fines de fertilización artificial (Zohar \& Mylonas, 2001). Por ello, es necesario el conocimiento y el desarrollo de tecnologías reproductivas, para el manejo sustentable de los gametos de peces de importancia económica, biológica y de todas aquellas especies en riesgo crítico, pues se requiere del estudio y del conocimiento de los factores que afectan la calidad de los gametos, como es el caso de los espermatozoides y sus modos de activación y fecundación (Dumorné et al. 2017; Herráez et al. 2017; Murakami et al. 2014; Rurangwa et al. 2004; Zohar \& Mylonas, 2001). Así como de todas aquellas metodologías, que son requeridas para evaluar apropiadamente la calidad de los espermatozoides empleados, para la fertilización artificial con fines acuícolas, de ciencia experimental básica, aplicada; también para la comprensión y la expansión de las fronteras de la biología espermática de los peces tropicales. En esta revisión detallada y selectiva de la bibliografía especializada, se ha hecho una amplia descripción de los conceptos, términos necesarios que permitirán a cualquier lector especialista o no en el tema, comprender las bases biológicas, fisiológicas y metodológicas necesarias para evaluar la calidad espermática de los peces.

\section{Espermatogénesis en los peces}

Los espermatozoides son el producto final derivado de un proceso altamente organizado y complejo de maduración gonádica de los machos, que es llamado espermatogénesis (Schulz et al. 2010), el cual implica la formación de cuatro células haploides, todas ellas especializadas y capacitadas para fertilizar y entregar los genes (material genético) del núcleo espermático a un óvulo (Ciereszko et al. 2017; Herráez et al. 2017; Schulz et al. 2010, Rurangwa et al. 2004; Zohar \& Mylonas, 2001). La espermatogénesis está sujeta a múltiples estímulos del ambiente (fotoperiodo, temperatura, disponibilidad de alimento), de la fisiología y del control hormonal del organismo (Zohar \& Mylonas, 2001).

En los peces teleósteos, se ha podido observar dos tipos de espermatogénesis: el cístico, en el cual el proceso se lleva a cabo dentro del lóbulo gonádico y el semicístico en el cual el desarrollo se realiza fuera del lóbulo gonádico, como es el caso de Ophidion sp. (Mattei et al. 1993). En ambos tipos el proceso es metamórfico 
y está dividido en tres diferentes fases: (I) mitótica con espermatogonias; (II) meiótica con espermatocitos primarios y secundarios; y (III) espermiogénesis con espermátidas que darán origen a espermatozoides haploides (Billard, 1986; Herráez et al. 2017; Schulz et al. 2010) bajo desarrollo normal, ya que en algunas ocasiones hay irregularidades de interés evolutivo, genético y biológico, que pueden dar origen a endomitosis con presencia de espermatozoides con niveles diferentes de contenido genético como son los diploides, tetraploides, etc. (Arias-Rodriguez et al. 2010; López-Hernández, 2017, Herráez et al. 2017; Zohar \& Mylonas, 2001).

Las espermatogonias son células que se clasifican en primarias y secundarias, la primera de ellas tiene la capacidad de proliferar y autorenovarse por mitosis, dando nuevas espermatogonias primarias o bien, diferenciarse a las secundarias, que desarrollan a espermatocitos. Los cuales se dividen en dos fases, primarios y secundarios; que se transformaran en espermátidas que sobrellevarán cambios estructurales y funcionales como son la formación del flagelo, la pieza media y la cabeza, todo ello dará origen a espermatozoides maduros, que tendrán la capacidad de fertilizar un óvulo (Dzyuba \& Cosson, 2014; Herráez et al. 2017).

Los espermatozoides haploides (1n), contenidos en los testículos, re- quieren transitar por varios cambios fisiológicos durante la maduración, con el fin de responder al choque osmótico que activará la capacidad fertilizante (Alavi et al. 2009; Dumorné et al. 2017). Durante la espermiación, los espermatozoides se dirigen de los testículos hacia la papila genital a través del ducto espermático, cuyo fluido seminal es de $\mathrm{pH}$ básico, rico en diversas sales como sodio, potasio, calcio, magnesio, entre otras (Alavi et al. 2009; Dumorné et al. 2017; Mylonas et al. 2017) que condicionan para cada especie por osmolaridad del líquido seminal única (Dumorné et al. 2017), siendo ello un atributo esencial para la activación de los espermatozoides que depende del hábitat particular de cada especie de pez.

\section{Generalidades de la morfología espermática en peces}

A través de los procesos de selección natural, los arreglos microestructurales de las células espermáticas han optimizado las estrategias de fertilización de acuerdo con las particularidades reproductivas de cada especie (Birkhead et al. 2009; Herráez et al. 2017; Rurangwa et al. 2004). Numerosos trabajos, enfocados al conocimiento de la morfología de las células espermáticas de peces, han mostrado la diversidad de formas y la composición estructural y ultraestructural de los espermatozoides (Herráez et al. 2017; Rurangwa et al. 2004). Estos 
han sido útiles, para comprender algunos aspectos taxonómicos y relaciones evolutivas de cada familia (Islam \& Akhter, 2011).

En casi todas las especies, la anatomía de los espermatozoides consiste de tres segmentos: cabeza, pieza media y flagelo. La cabeza de acuerdo a la especie varia en forma y tamaño, transporta los genes del macho (Ciereszko et al. 2017) en condición haploide en un núcleo de formas variables y en la mayoría de los teleósteos es ausente de acrosoma, debido a la presencia del micrópilo en el óvulo (Islam \& Akhter, 2011; Jamieson, 1991; Zohar \& Mylonas, 2001). La pieza media está sujetada a la cabeza de los espermatozoides, constituida principalmente por mitocondrias que contribuyen con la energía mediada por el ATP (Dzyuba et al. 2017; Saudrais et al. 1998 Rurangwa et al. 2004), para el movimiento flagelar hay dos centriolos, el proximal y distal que durante la espermiogénesis utilizarán uno o los dos centriolos como cuerpo basal para originar uno o dos flagelos respectivamente (Jamieson, 1991). El flagelo, es el aparato motil para alcanzar y penetrar el óvulo por el canal micropilar (Dzyuba \& Cosson, 2014; Jamieson, 1991), en su mayoría esta constituido por el axonema en arreglo de nueve pares de microtúbulos periféricos y un par central llamado complejo 9+2 que está recubierto por la membrana plasmática, y confiere forma de cinta o de remo (aletas flagelares) (Jamieson, 1991), que de acuerdo a Tabares et al. (2005), posiblemente es una ventaja evolutiva para favorecer el movimiento del espermatozoide en el medio acuoso. Por otra parte, en algunas especies de la familia Mormyridae o peces elefantes de fertilización externa, el flagelo está ausente y su única forma de locomoción es de tipo ameboideo (Jamieson, 1991).

Tales estructuras y componentes que integran la célula espermática, son crucialmente importantes para determinar la calidad del desempeño espermático (Linhart et al. 2003; Saudrais et al. 1998). Mediante la tinción de un frotis espermático con giemsa al 20\% y con el empleo de un microscopio óptico, provisto de una cámara con un programa para la visualización de imágenes, es posible observar los atributos básicos de la anatomía extracelular de los espermatozoides, como son la cabeza y el flageló, tal y a como puede observarse en las imágenes mostradas de la Figura 1, que dan como ejemplo las variaciones en tamaño y formas de los espermatozoides del bagre tropical Rhamdia laticauda (Fig. 1A, 1B), los del pejelagarto tropical Atractosteus tropicus (Fig. 1C, 1D) y los de la mojarra del Nilo Oreochromis niloticus (Fig. 1E, 1F). 

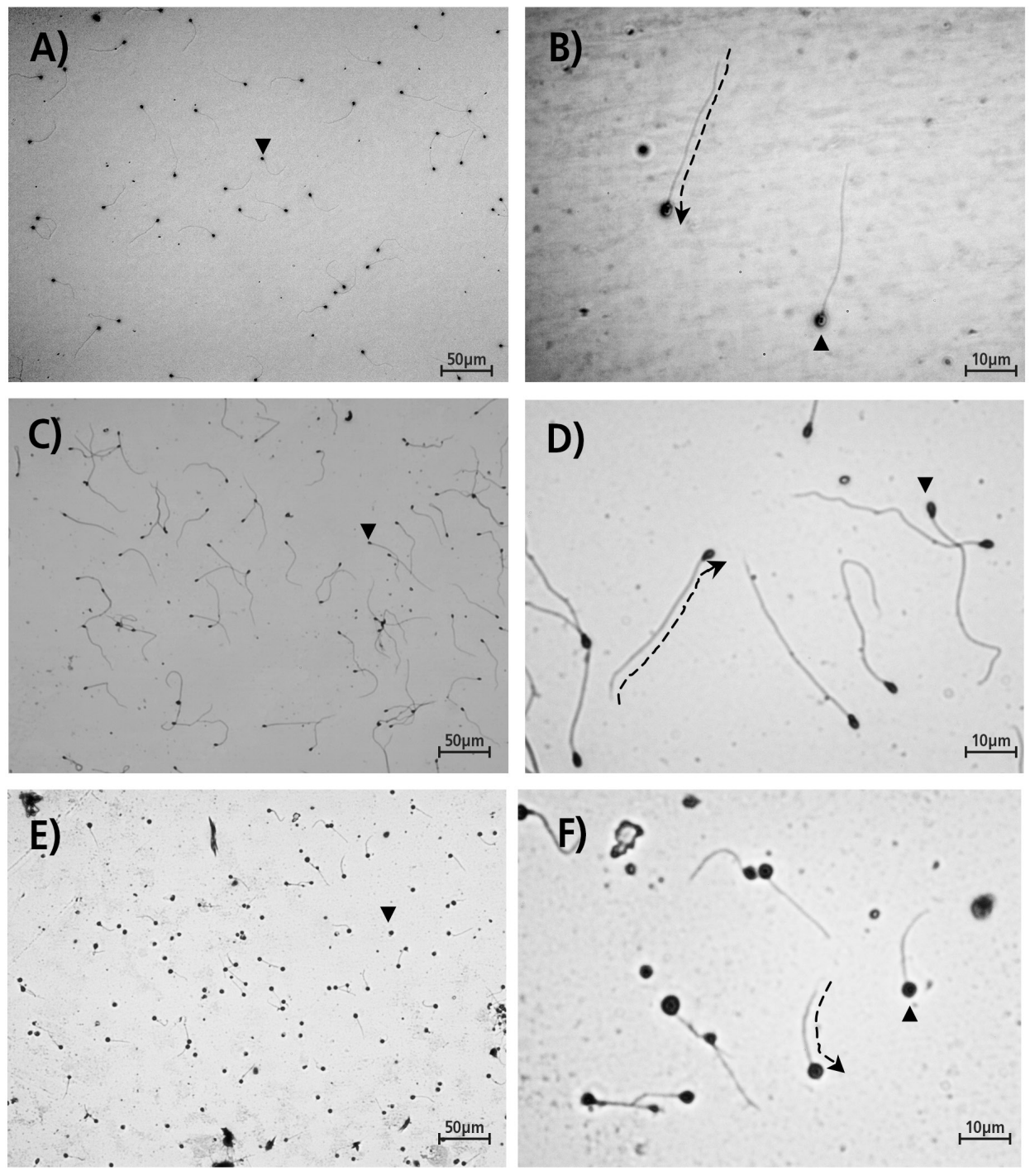

Fig. 1. Paisaje característico de los espermatozoides a $12.5 \mathrm{X}$ y $50 \mathrm{X}$ del bagre tropical Rhamdia laticauda (A, B), el pejelagarto tropical Atractosteus tropicus (C, D) y la mojarra del Nilo Oreochromis niloticus (E, F), mostrando con un triángulo sólido $(\boldsymbol{\nabla})$ la cabeza espermática y la trayectoria flagelar con una flecha en línea discontinua. Imágenes originales de los autores.

Fig. 1. Typical sperm landscape at $12.5 \mathrm{X}$ and $50 \mathrm{X}$ from the tropical catfish Rhamdia laticauda (A, B), the tropical gar Atractosteus tropicus (C, D) and the Nile cichlid Oreochromis niloticus (E, F), pointing with a solid triangle ( $\boldsymbol{\nabla})$ the sperm's head and the flagellar trajectory with an arrow on interrupted line. Original pictures from authors. 


\section{La calidad espermática en peces}

La calidad espermática es la habilidad y la capacidad de un espermatozoide para fertilizar exitosamente un óvulo y activar el desarrollo de un embrión viable (Bobe \& Labbé, 2010, Dumorné et al. 2017; Fauvel et al. 2010; Rurangwa et al. 2004). La viabilidad del embrión, es la suma de la calidad del óvulo y del espermatozoide (Dzyuba \& Cosson, 2014). Desde el punto de vista biológico, en condiciones naturales, los espermatozoides de dos o más machos de una misma especie compiten por fertilizar los óvulos, en dependencia del desempeño espermático, con el fin de asegurar mayor número de progenie (López-Hernández, 2013; López-Hernández, 2017; Osorio-Pérez, 2017).

En acuacultura, la importancia del diagnóstico del semen predice la capacidad fecúndate del eyaculado y contribuye a mejorar las técnicas de fertilización in vitro y el desarrollo de metodologías de crioconservación o biotecnologías aplicadas al mejoramiento genético (Bobe \& Labbé, 2010; Fauvel et al. 2010). Para considerar competentes los espermatozoides de un pez, estos deben cumplir con los requerimientos básicos de calidad espermática (Herráez et al. 2017; López-Hernández, 2013; 2017; Osorio-Pérez, 2017; Rurangwa et al. 2004). En la evaluación de la calidad espermática, es válido cualquier parámetro cuantitativo o cualitativo que se relacione directamente con la habilidad fecundante del espermatozoide, entre ellos se puede mencionar: el tiempo de movimiento o periodo por el cual los espermatozoides están activos, tipo de movimiento o características del movimiento espermático, porcentaje de células motiles o número de células que se observan en movimiento, número de espermatozoides o cantidad de células espermáticas por volumen de muestra (Bobe \& Labbé, 2010; Fauvel et al. 2010; Rurangwa et al. 2004) e integridad (o estado de deterioró) de las estructuras de la célula espermática (Herráez et al. 2017).

\section{La recolección de semen}

Un factor importante a considerar en la evaluación de la calidad del semen, es el método de recolecta empleado. Generalmente, cuando los reproductores machos están maduros, se reconocen porque liberan el líquido seminal ante suave presión del abdomen (Aas et al. 1991; Billard et al. 1995a; Dreanno et al. 1998). Los organismos deben (de preferencia), anestesiarse y secarse con una tela para evitar el contacto con el agua (y heces fecales), ya que esta activa la motilidad de los espermatozoides al mezclarse durante el manejo de los animales y las muestras de semen (Arias-Rodriguez, 2001; López-Hernández, 2013; 2017; Osorio-Pérez, 2017). El semen extraído puede ser recolectado mediante el empleo de 
un tubo graduado, una jeringa o una cánula (Dreanno et al. 1998). Con el empleo de un tubo de ensayo, jeringa y tubo capilar, no hay riesgo de daño a los testículos (Rodríguez-Gutiérrez, 1992). Sin embargo, su empleo ocasiona contaminación por excremento y orina, se evita con, no alimentar y purgando los peces a lo largo de un día (Dreanno et al. 1998). Cuando la canulación es empleada, se evita la contaminación del líquido seminal por heces y orina, pero existe la posibilidad de daño testicular, si no se tiene un buen conocimiento de la anatomía del pez (Dreanno et al. 1998; Glogowski et al. 2000; Rodríguez-Gutiérrez, 1992). Cuando se trata de peces pequeños, como los locha (Arias-Rodriguez et al. 2010) u otros de uso ornamental, el empleo de tubos capilares es de mucha utilidad para la recolección de semen.

Técnicas tradicionales y avanzadas para la evaluación de la calidad espermática

El control de la calidad espermática es un tema relevante en la industria acuícola o de interés creciente para estudios de biología reproductiva, ya sea para la producción de especies comerciales establecidas o para la introducción de nuevas especies con alto interés comercial (Cabrita et al. 2014; Herráez et al. 2017; Rurangwa et al. 2004). Por ello, las particularidades genéticas y fisiológicas de un espermatozoide viable, para ferti- lizar exitosamente un óvulo (Herráez et al. 2017; Rurangwa et al. 2004) pueden permitir el desarrollo de un espécimen normal (Álvarez et al. 2009; Herráez et al. 2017; Murakami et al. 2014). En el apareamiento o desove, la presencia en abundancia de gametos con buena calidad son liberados por las especies de fertilización externa en hábitats específicos como son cuerpos de agua dulceacuícolas, salobres y marinos donde el desbalance entre la osmolaridad del hábitat acuático y la del líquido seminal, son en conjunto los detonantes de la actividad espermática, que es uno de las parámetros que dan pauta al éxito de la fertilización (Rurangwa et al. 2004).

Tradicionalmente, las características apropiadas de las muestras de semen, han sido evaluadas mediante el análisis de diferentes parámetros como la concentración de células espermáticas, la motilidad o la actividad que es considerada como el tiempo de actividad celular, los porcentajes de células activas (Cabrita et al. 2014; Rurangwa et al. 2004) y los porcentajes de fertilización (Arias-Rodriguez et al. 2004; Rurangwa et al. 2004). En años recientes, en las prácticas de evaluación de los espermatozoides, se inició con el uso de la morfología de las células espermáticas, la integridad de la membrana celular y nuclear, el contenido energético y las pruebas complejas, que incluyen herramientas 
moleculares para identificar células vivas, muertas y en apoptosis (Cabrita et al. 2014; Herráez et al. 2017; Rurangwa et al. 2004).

La evaluación de la motilidad espermática y los porcentajes de fertilización, han sido los parámetros de mayor uso para determinar la calidad del semen en mamíferos y en algunas especies acuáticas. Es sabido que la integridad espermática se encuentra asociada con los porcentajes de fertilización, al ser óptimos cuando la calidad espermática es buena y pobres cuando la calidad es baja (Ciereszko et al. 2005; Costache et al. 2012; Herráez et al. 2017). Afortunadamente, métodos analíticos con mayor objetividad han surgido, y tales exámenes incluyen el Análisis Espermático Asistido por Computadora (AEAC o CASA), la electroforesis de células individuales (ensayo cometa o de dispersión de componentes celulares), la viabilidad espermática y apoptosis por citometría fluorescente automática. Así mismo, la Microscopia Electrónica de Barrido, la Microscopia Electrónica de Transmisión, el ensayo túnel y del metabolismo de ATP; entre otros (Cabrita et al. 2014; Herráez et al. 2017; Rurangwa et al. 2004) han sido empleados recientemente como nuevas herramientas, para la evaluación rápida y confiable de la calidad espermática de especies emergentes de peces para su apro- vechamiento acuícola (Cabrita et al. 2014; Herráez et al. 2017), con la desventaja de los altos costos de su empleo.

El desarrollo de nuevas técnicas y métodos alternativos para evaluar objetivamente la calidad espermática en peces, ha dado pauta a mejorar los criterios de evaluación y los resultados durante su aplicación en programas de producción masiva de larvas de peces (Herráez et al. 2017). Métodos alternativos como es el empleo de Microscopia Electrónica de Transmisión y Microscopia Electrónica Barrido, sistemas computarizados (Sperm Class Analyzer ${ }^{\circledR}$ CASA System), prueba de dispersión de ADN (ensayo cometa), citometría fluorescente para determinar la viabilidad celular por tinción con Ioduro de propidio y Anexina V (Invitrogen $\left.{ }^{\circledR}\right)$, han permitido el análisis detallado del efecto de diversos agentes como la luz ultravioleta, críoprotectores, diluyentes espermáticos, metales pesados, contaminantes, etc., empleados en algunas ocasiones con propósitos biotecnológicos y de conservación temporal y a largo plazo (Cabrita et al. 2014; Herráez et al. 2017; Rurangwa et al. 2004).

\section{El tiempo de motilidad o actividad espermática}

El tiempo de motilidad o periodo de actividad de los espermatozoides posterior a su activación con 
un medio acuso, se ha venido expresando en términos de tiempo que es medido particularmente en segundos, este parámetro inicia desde el momento en que los espermatozoides son activados con agua o fluido ovárico, hasta la disminución o cese total del movimiento flagelar (Arias-Rodriguez, 2001). Para la evaluación de la motilidad, es recomendable emplear una dilución alta o volumen mayor de agua (o activador) en relación con el volumen inicial de la muestra de semen, hecho que sincroniza la activación de los espermatozoides de lo contrario, se puede presentar incertidumbre en la motilidad observada ya que la activación podría ser heterogénea (Arias-Rodriguez, 2001; Rurangwa et al. 2004).

La duración de la motilidad en el ambiente natural, varía entre especies y coincide con el tiempo de fertilización del espermatozoide. Generalmente, este tiempo de motilidad es influenciado por el hábitat del cual se origina el reproductor macho, por ejemplo: marino o dulceacuícola (Wootton \& Carl, 2014; Wootton \& Smith, 2014a, b). En la mayoría de los peces que desovan en agua marina (medio hipertónico), los espermatozoides mantienen periodos de motilidad más prolongados que en especies que desovan en ambientes dulceacuícolas (medio hipotónico) (Tabares et al. 2005). Sin embargo, son el nú- mero de mitocondrias de cada especie las que proveen la energía (ATP o Adenosin Trifosfato) necesaria para el movimiento flagelar (Dziewulska et al. 2012; Tabares et al. 2005), por lo que el tiempo de vida motil del espermatozoide no solo depende de las condiciones extrínsecas (cantidad de agua, temperatura y osmolaridad), sino también, de la cantidad de ATP emitida por las mitocondrias al flagelo (Dziewulska et al. 2012; Rurangwa et al. 2004).

El contenido de ATP intracelular, está relacionado con la capacidad de movimiento del espermatozoide y con el tiempo total de motilidad (Dziewulska et al. 2012), al declinarse este después de la activación hasta en un $50 \%$, lo que sugiere que una muestra con reducido tiempo de movimiento pudo haber sido activada inicialmente por agua u orina durante su extracción, al declinar el contenido de ATP y en consecuencia el movimiento (Billard et al. 1995a; Perchec et al. 1995; Rurangwa et al. 2004).

Los espermatozoides típicamente, están inmóviles en el lumen de la red de túbulos seminíferos de los testículos y son activos después de ser diluidos en un medio externo, como es el caso del agua originaria del pez sea marino o dulce acuícola (Billard et al. 1995b), dicha condición es importante cuando se evalúa la motilidad (Billard et al. 1995a). Las concentraciones 
altas de cationes $\mathrm{K}+$ en el líquido seminal, inhiben la motilidad de los espermatozoides en algunas especies (Billard et al. 1995a). El pH de la solución activadora (p. e. marina o dulce) también afecta la motilidad, al ser necesario (en ocasiones) ajustar el pH de la solución a valores ácidos o alcalinos, esto depende de la especie en estudio (Arias-Rodriguez, 2001).

La osmolaridad de la solución activadora, afecta los porcentajes de células activas, como ha sido observado en experimentos con el bagre tropical $R$. laticauda (Jiménez-Trinidad, 2016). En el caso de los peces de agua dulce esta debe ser hipotónica y para los peces marinos hipertónica (Billard et al. 1995a).

Durante la evaluación de la motilidad es necesario hacer una dilución alta (p. e. 1:1000) con el fin de iniciar una activación sincrónica de los espermatozoides. En diluciones bajas no todos los espermatozoides se activan (activación heterogénea), al ser esta progresiva durante varios minutos después de realizada la activación. Dicha característica genera imprecisiones de la intensidad y la duración de la motilidad. Por consiguiente, es importante establecer que niveles de dilución insuficientes e irregulares, pueden ser la explicación de muchas de las discrepancias señaladas en la literatura para una misma especie (Billard et al. 1995a; Rurangwa et al. 2004).
El semen resulta difícil de mezclar debido a su viscosidad, por lo que deben hacerse diluciones altas o agitar adecuadamente las muestras, aunque esto puede dañar las células espermáticas (Billard et al. 1995a). Un procedimiento adecuado consiste en realizar primero una dilución en una solución extendedora de la motilidad (solución que no activa a los espermatozoides, sino que los mantiene en latencia) como las empleadas por Lahnsteiner \& Patzner (1998), en Boops boops, Diplodus sargus, Mullus barbatus y Trachurus mediterraneus, que generalmente debe tener la misma presión osmótica (misma osmolaridad) que el fluido seminal (lo que puede lograrse al adicionar $\mathrm{K}+$ a una concentración adecuada).

La activación de los espermatozoides es realizada en el segundo paso, bajo el microscopio, al poder emplear $1 \mu 1$ de semen en 19 microlitros (1:20) de solución activadora que tenga una presión osmótica apropiada (Cosson et al. 2008).

Diferentes métodos son empleados con el fin de medir la motilidad. El de más uso se refiere a la duración total en segundos, asociado al tipo de movimiento del flagelo, al seguir comúnmente una escala gradual basada en los atributos del movimiento espermático como la descripción tradicional que ha sido señalada por Menkveld \& Kruger (1996). 
En la estimación de la motilidad, se considera también el porcentaje de células activas al poder emplearse el criterio (subjetivo) sugerido por Aas et al. (1991), en el cual el porcentaje de células motiles se define en una escala del 0 al 100\%, con intervalos de 10 (p. e. $10,20,30,40 \%$, etc.).

Métodos modernos que permiten evaluar la motilidad de los espermatozoides, consisten en medir la frecuencia con la cual el flagelo es agitado, análisis que se realiza mediante estroboscopía (Cosson et al. 2008). Con el análisis de fotografías y/o videos del movimiento de la cabeza y/o del flagelo, es posible medir la velocidad de desplazamiento del espermatozoide en un periodo de tiempo (Cosson et al. 2008; Herráez et al. 2017). Recientemente, la motilidad se está estudiando mediante procedimientos que permiten la desmembranación y la reactivación in vitro (Linhart et al. 2003; Saudrais et al. 1998).

\section{Tipo o grado de movimiento}

Otra variable importante es el tipo o grado de movimiento que es expresado como la dirección que la célula toma en su trayectoria motil, esto indica si el espermatozoide está en su máxima capacidad progresiva para fecundar el óvulo desde el momento de la activación, es decir, que el flagelo está en constante movimiento vigoroso por tiempo prolongado durante la vida motil del esper- matozoide (Arias-Rodriguez, 2001; Rurangwa et al. 2004). El tipo de movimiento, se puede estimar cualitativamente por microscopia óptica y para ello se emplean escalas preestablecidas como la propuesta por Menkveld \& Kruger (1996), donde se describen detalladamente los patrones de movimiento de los espermatozoides activados y a como se describe a continuación:

Grado 4. Máximo movimiento progresivo de los espermatozoides (óptimo para la fertilización).

Grado 3 Disminución del movimiento progresivo de los espermatozoides, junto con el incremento de los movimientos laterales que promedian aproximadamente de dos a tres anchos el cuerpo del espermatozoide (apropiado para la fertilización).

Grado 2. Poco o ningún movimiento progresivo y movimientos laterales circulares de una o dos veces el ancho del cuerpo del espermatozoide (no apropiado para la fertilización).

Grado 1. Muy poco movimiento de la cabeza de los espermatozoides, junto con el decremento del movimiento del flagelo (sin capacidad de fertilización).

Grado 0. Sin motilidad, ni movimiento progresivo (movimiento frontal) de los espermatozoides ( $\sin$ capacidad absoluta para la fertilización). 


\section{Porcentajes de células motiles}

Al relacionar el tiempo y el tipo de movimiento, es fácil estimar qué porcentaje o porcentajes de la alícuota espermática activada es viable, tal parámetro es evaluado al determinar el número subjetivo de células activas en un campo visual bajo el microscopio óptico, normalmente al emplear el objetivo de 40X, pues permite estimar las posibilidades del espécimen macho para competir por la fertilización (Arias-Rodriguez, 2001; Rurangwa et al. 2004). En la fertilización in vitro, los porcentajes de células funcionales deben ser óptimos $(>80 \%)$, porque los valores menores $(<70 \%)$, reducen significativamente la obtención de porcentajes aceptables de óvulos fecundados. Para ello, se puede emplear el criterio sugerido por Aas et al. (1991), en el cual el porcentaje de células motiles está definido en escala del $0 \%$ al $100 \%$ con intervalos de 10 , donde el $90 \%$ y $100 \%$ son óptimos para garantizar mayores porcentajes de óvulos fertilizados o de su empleo para experimentos de biología y biotecnología.

\section{Concentración o número de esper- matozoides}

La concentración de espermatozoides en el líquido seminal es con frecuencia empleado en la caracterización de la calidad del semen (Arias-Rodriguez, 2001; Billard et al. 1995a). El conteo del número de espermatozoides por mililitro de muestra espermática, se determina tradicionalmente con el empleo de un hematocitómetro o cámara neubauer (Arias-Rodriguez, 2001), un ejemplo de ello es lo indicado en la Figura 2A. El número de espermatozoides se puede estimar también por densidad óptica, mediante espectrofotometría o por la técnica del microhemátocrito (Rakitin et al. 1999; Rurangwa et al. 2004), la primera es la más precisa y rápida, pero con un alto costo del equipo. Últimamente, se utilizan los citómetros automáticos, con fácil operación y con altos estándares de precisión en los resultados que se obtienen, pero los costos del equipo, los reactivos y los consumibles hacen esta herramienta poco accesible para las prácticas acuícolas, al ser más común su empleo en experimentación (Fig. 2B, C, D) (Jiménez-Trinidad, 2016; López-Hernández, 2017; Osorio-Pérez, 2017).

El número de espermatozoides, también está relacionado con la estación reproductiva, el tratamiento hormonal, los porcentajes de fecundación y de la especie, la disponibilidad del alimento, las propiedades nutricionales del alimento y la calidad del agua (Murakami et al. 2014).

La cantidad de células espermáticas varía además entre individuos de la misma especie y entre las diferentes especies; por ello, es recomendable que dicho parámetro se determine en las muestras de semen, de cada uno de los reproductores machos seleccionados 


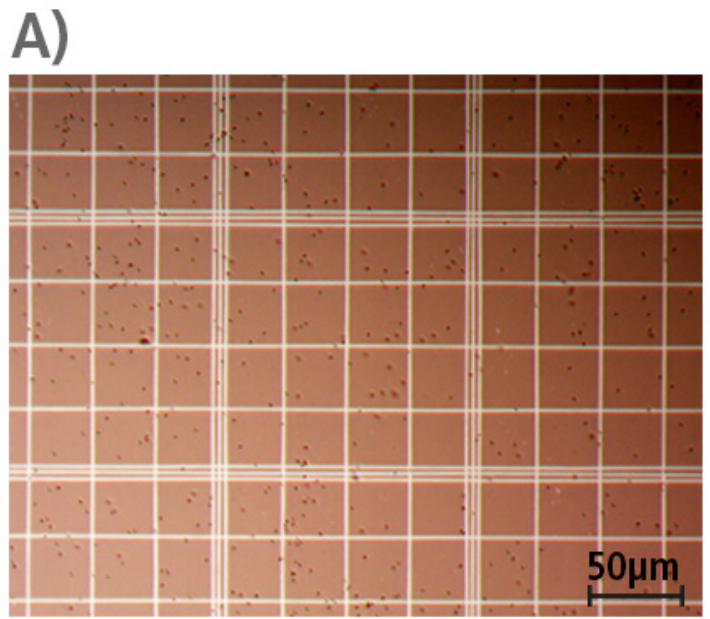

\section{B)}
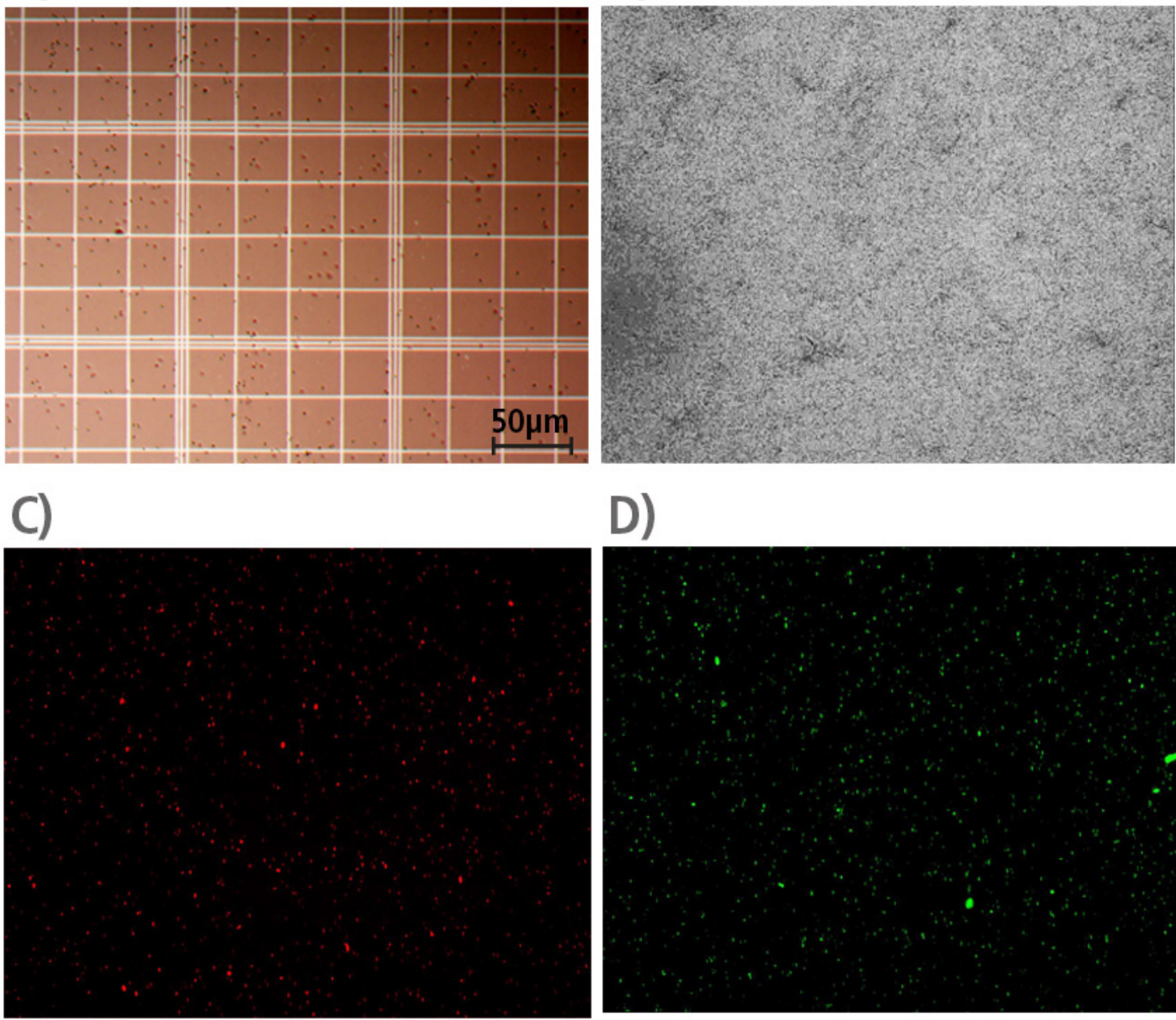

Fig. 2. Cuantificación del total de células espermáticas del bagre tropical Rhamdia laticauda mediante la cámara de Neubauer a $12.5 \mathrm{X}$ (A) y el citómetro automático a 16X en campo claro (B), y cuantificación de la viabilidad espermática por citometría automática en campo fluorescente, al emplear ioduro de propidio para células muertas (C) y anexina $\mathrm{V}$ para células en apoptosis (D). Imágenes originales de los autores.

Fig. 2. Total sperm cell count of the tropical catfish Rhamdia laticauda using the Neubauer chamber at $12.5 \mathrm{X}$ (A) and the automatic cytometer at $16 \mathrm{X}$ with bright field (B); and quantification of sperm viability by the automatic cytometer at fluorescent field, marked with propidium iodide for dead cells (C) and annexin $\mathrm{V}$ to detect apoptotic cells (D). Original pictures by authors. 
para los programas de producción masiva de larvas o bien para los experimentos que requieran de porcentajes altos de fertilización (Murakami et al. 2014). Es obvio que el número de espermatozoides, necesarios para fertilizar un óvulo es equivalente a una célula espermática por cada óvulo del pez, esto es en los casos muy precisos del programa de fertilización. Sin embargo, realmente no existe un valor o número preciso o recomendable de células espermáticas viables, debido a que los valores están en función del número de óvulos a fertilizar, un mínimo de 1000 espermatozoides puede garantizar la fertilización exitosa de 100 óvulos viables (Satterfield \& Flickinger, 1995).

Lo recomendable es emplear en los casos de bajo presupuesto, el índice de motilidad (I. M.) mínimo de 50, el cual se obtiene al multiplicar la graduación del movimiento espermático anteriormente señalado, por el porcentaje de células activas (Satterfield \& Flickinger, 1995). Dicho parámetro se ha empleado con éxito en la perca Stizostedion vitreum (Satterfield \& Flickinger, 1995), en el botete diana Sphoeroides annulatus (Arias-Rodriguez et al. 2004) y en el bagre tropical R. laticauda (López-Hernández, 2013, 2017) con índices de motilidad de 400, mismo que se obtuvo al multiplicar el tipo de movimiento equivalente a 4 por el $100 \%$ de células activas.

\section{La capacidad de fertilización}

La capacidad de fertilización es un estimador que permite evaluar la calidad del semen. Este procedimiento se emplea en estudios referidos a la inseminación artificial y preservación de espermatozoides (Billard et al. 1995a; Lahnsteiner et al. 1998; Rurangwa et al. 2004). De acuerdo con Billard et al. (1995a), la capacidad de fertilización integra un factor independiente como es la calidad de los óvulos, la interacción entre gametos y fluidos seminales/ováricos. La inseminación se realiza a diferentes porcentajes de dilución espermática, con el propósito de establecer un número mínimo de espermatozoides que puedan fertilizar al 100\% ciertos gramos de óvulos (Billard et al. 1995a).

\section{La densidad del líquido seminal}

La densidad del líquido seminal es otro factor importante en su calidad, pues durante la toma de muestras se observa con frecuencia que algunos reproductores manifiestan abundante fluidez seminal, muy posiblemente tengan densidad baja de espermatozoides (Rurangwa et al. 2004), mientras que en caso contrario, el semen con densidad alta, mantiene mayor número de células espermáticas por mililitro de muestra (Arias-Rodriguez et al. 2004). La densidad, se puede determinar en el laboratorio húmedo o en campo cuando no se cuenta con un espectrofotómetro, mediante la 
fórmula: $\mathrm{D}=\mathrm{P} / \mathrm{V}$; donde $\mathrm{D}=$ densidad, $\mathrm{P}=$ peso en gramos de la muestra y $\mathrm{V}$ corresponde al volumen en mililitros de la muestra (Rodríguez-Gutiérrez, 1992).

\section{Morfología y viabilidad por tinción}

La determinación de la morfología y la viabilidad de una muestra de semen es un requisito importante, aunque de poco uso, debido a lo laborioso e impráctico del método, cuando los resultados son requeridos de inmediato (López-Hernández, 2017; Osorio-Pérez, 2017; Rurangwa et al. 2004). Sin embargo, cuando se trata de procedimientos encaminados a la criopreservación de semen o al apoyo de metodologías en las cuales no se requiere información inmediata (p. e. motilidad), este es un procedimiento que proporciona información adicional respecto a los porcentajes de fertilización y sobrevivencia.

La prueba de viabilidad consiste en determinar el número de espermatozoides vivos y muertos, al emplear la tinción (de un frotis delgado de semen) con eosina-nigrosina (Álvarez et al. 2009; Fribourgh, 1966), los espermatozoides muertos se tiñen de rojo y los vivos no. El empleo del procedimiento anterior aunque es económico, se debe realizar y valorar, porque su aplicación no resulta en un procedimiento práctico para cualquier especie (Arias-Rodriguez, 2001).
La prueba tradicional para la determinación de la morfología consiste en teñir un frotis delgado de semen con azul de metileno y con fucsina fenólica de Ziehl-Nielsen (Rodríguez-Gutiérrez, 1992), en el que es posible detectar (a 100X) anormalidades morfológicas como espermatozoides con doble flagelo, gotas de citoplasma en el flagelo próximas a la cabeza, flagelos curvados o doblados y cabezas sin flagelo (Miliorini et al. 2011; López-Hernández, 2017). Por otro lado, los métodos de tinción con colorantes fluorescentes, ofrecen mayor precisión debido a la particularidad bioquímica de los fluorocromos que se emplean para determinar estados fisiológicos específicos de la célula (p. e. vivos, muertos y en apoptosis) (Chan et al. 2012). Actualmente, los colorantes fluorescentes más utilizados son azul de tripano, SYBR 14 (Chalah \& Billard, 1998) Rhodamina 123, Hoechst 33258, diacetato de carboxifluoresceina, ioduro de propidio (Brana et al. 2002) y bromuro de etidio, Anexina V (Schutte et al. 1998; Vermes et al. 2000; Koopman et al. 1994; Zhang et al. 1997), que facilitan un análisis más objetivo y cuantitativo con equipos alimentados con luz ultravioleta que excitan a los fluorocromos al emitir un color específico, tales equipos pueden ser los microscopio de fluorescencia y citómetros de flujo. Métodos con mayor resolución son los que 
emplean observación directa de las células espermáticas y están basados en las herramientas de microscopia electrónica (Osorio-Pérez, 2017; Psenicka et al. 2007; López-Hernández, 2017), las cuales se estarán comentando en los apartados siguientes.

Citometría automática y la viabilidad espermática

El citómetro es un instrumento que puede medir ciertas propiedades físicas como son tamaño, forma y densidad, y otras particularidades celulares después de que estas son incubadas con componentes orgánicos especiales (Chapman, 2000; Jiménez-Trinidad, 2016; López-Hernández, 2017; Osorio-Pérez, 2017). Los avances en los fluidos, en electrónica, ordenadores y software, laser de alta potencia como el diodo emisor de luz (LED), y tecnologías de lentes ópticos como detector de imágenes, han permitido el desarrollo de una nueva generación de sistemas accesibles, como la citometría basada en imágenes automatizadas. También, el desarrollo y la disponibilidad de nuevos colorantes fluorescentes, han hecho de esto una herramienta muy flexible y en la que es posible correlacionar hasta diez parámetros en una sola lectura (Chapman, 2000; Vermes et al. 2000). En contraste con las técnicas tradicionales que aportan menor cantidad de datos y requieren de mayor tiempo para su desarrollo.

La citometría de flujo, ha sido empleada en estudios de biología de la reproducción para la evaluación de las características e integridad de la membrana de células espermáticas. El método de doble tinción permite medir con precisión la viabilidad de diferentes poblaciones de células (Chan et al. 2012; López-Hernández, 2017; Osorio-Pérez, 2017). La capacidad de la citometría de fluorescencia, para cambiar fácilmente su módulo óptico, permite la excitación y la emisión de estos tipos de colores, lo que da la posibilidad de experimentar con varios tintes y discriminar células en diferentes estadios o condiciones fisiológicas, por ejemplo: vivas, muertas y en apoptosis (Chan et al. 2012; López-Hernández, 2017; Osorio-Pérez, 2017).

Las características dependen de las diferencias en la permeabilidad de la membrana plasmática de las células espermáticas vivas, muertas y apoptóticas en los tintes empleados para teñir el ADN, como el ioduro de propidio, bromuro de etidio y Hoechst-33342, uno puede discriminar a las células vivas, muertas y apoptóticas. El ioduro de propidio penetra en las células necróticas o muertas, intercalándose con el ADN, y causa fluorescencia roja. La Anexina V, muestra una interacción fuerte y específica con la fosfatidilserina en presencia de $\mathrm{Ca}+$ que se da por pérdida de simetría de la membrana plasmática (Vermes et al.2000), la cual es visualizada por fluorescencia verde o azul tenue, con la que es posible detectar las células en apoptosis. En el 
caso particular de las células espermáticas vivas, estas no se tiñen y son observadas como objetos transparentes durante los análisis.

La homeóstasis es mantenida en organismos multicelulares por el balance entre la proliferación celular y la muerte celular. El término apoptosis o muerte celular programada, se define como un programa de muerte celular genéticamente codificado, el cual es morfológicamente y bioquímicamente distinto de la necrosis o muerte accidental (Vermes et al. 2000).

Tipos diferentes de muerte celular: Apoptosis (tipo I), muerte celular asociada con autofagia y pérdida de la integridad de la membrana plasmática (tipo II) y fuga del contenido intracelular (necrosis o tipo III) (Koopman et al. 1994). La apoptosis es un mecanismo de renovación de células no deseadas por el sistema inmune, esta es caracterizada por la condensación de cromatina, reducción del volumen celular y división del ADN por endonucleasas en fragmentos grandes de oligonucleosomas, además es acompañada por la pérdida de asimetría fosfolípidica de la membrana (Koopman et al. 1994). Existen diversas técnicas para determinar y cuantificar el fenómeno apoptótico, dentro de las metodologías más comunes para la detección de apoptosis se encuentran: el electroforesis en gel, en la cual el ADN fragmentado puede ser observado como bandas de tamaño equivalente a múltiples oli- gonucleosomas o de un único nucleosoma, y la viabilidad por tinción mediante marcadores como: Anexina V, ioduro de propidio, eosina-nigrosina, azul de tripano, etc. Además, métodos como perdida de la viabilidad celular o condensación de ADN, han sido también empleados en el monitoreo de la apoptosis. Sin embargo, los cambios morfológicos y la degradación de la cromatina son la base de tales ensayos y ocurren después de la apoptosis (Zhang et al. 1997).

En los primeros estadios de la apoptosis un cambio en la superficie de la célula es observado, esta es la translocación de la fosfatidilserina del interior de la membrana plasmática al exterior, que queda expuesta en la superficie de la célula. La Anexina "V" es una proteína de unión-fosfolipidica dependiente de $\mathrm{Ca}+$, con alta afinidad por la fosfatidilserina y es una de las más usadas para detectar apoptosis mediante el análisis citométrico fluorescente, al marcar la pérdida de simetría de la membrana, durante el inicio del proceso apoptótico (Zhang et al. 1997).

El análisis por citometría fluorescente de células (Fig. 2C, D), es objetivo, ya que mide la cantidad de tinción asociada o hibridizada con las células de una manera más completa, este puede analizar millones de células en segundos y puede evaluar múltiples tinciones fluorescentes, asociadas con espermas individuales (Graham, 2001). La citometría de flujo, es una 
técnica atractiva, debido a que permite la caracterización de cada espermatozoide en términos de función celular e integridad de sus diferentes compartimentos, así como, también la identificación de subgrupos sobre un gran número de células. Por medio del análisis de citometría de flujo, la detección de moléculas involucradas en la muerte apoptótica, el análisis del ciclo celular y la determinación de la actividad de las caspasas han sido también evaluadas con éxito en células espermáticas.

Evaluación de las microestructuras espermáticas por Microscopia Óptica (MOP)

El análisis de la morfología espermática típica es el criterio directo más importante para evaluar la calidad de una muestra de semen. La correcta evaluación depende del modo de preparación, fijación y del método de tinción de las células gaméticas (van der Horst \& Maree, 2010).

Una técnica de tinción debe causar el menor cambio en las dimensiones y las formas como sea posible, con el fin de evaluar de manera confiable las características morfométricas de cada componente celular. Las diferentes morfologías espermáticas por microscopia óptica, son usualmente establecidas por la tinción de las muestras de semen y al examinar la laminilla bajo un microscopio óptico, con los objetivos de 40X o
$100 \mathrm{X}$ con contraste de fases negativo, al ajustar correctamente el brillo del campo (Fig. 1), seguido por el análisis de las imágenes capturadas.

Técnicas de tinción diferentes han sido desarrolladas para el análisis espermático por microscopia óptica como: Hematoxilina-eosina, azul de toluidina, giemsa, Wright, naranja G, tinción con azul de eosina-anilina, método de Shorr, Papanicolaou, método de Berg, tinción verde claro, naranja de acridina y tinción verde de Janus (Aksoy et al. 2012; Serafini et al. 2014). Sin embargo, el desarrollo del Análisis Automatizado para la Morfología Espermática (AAME) o el Sistema de Análisis Espermático Integrado (SAEI), ha llevado al incremento en el número de estudios sobre la morfología en espermatozoides de animales, principalmente en mamíferos mediante el empleo de tinciones que da un mejor contraste de fondo.

El empleo combinado por sistemas computarizados y métodos de tinción como Diff-Quick, Hemacolor, Spermac, SpermBlue, actualmente permite el análisis automático de rutina de la forma de los espermatozoides y fomenta el desarrollo del análisis de imágenes para caracterizarlos de manera rápida (van der Horst \& Maree, 2010) en otros grupos taxonómicos como es el caso de varias especies de mamíferos, lo que incluye a nuestra especie Homo sapiens. En el caso de 
los peces, la adaptación de tales métodos en el futuro, requerirán de su validación. Sin embargo, la morfología de los espermatozoides en peces, es tan variada que requiere de la estandarización de la forma celular para cada especie previa a procesos de medición. Por ello, los métodos subjetivos por microscopia óptica y el empleo de las nuevas tinciones, permiten la evaluación de espermatozoides en tiempo real, al ser este un método barato y de fácil acceso (Aksoy et al. 2012; Esteso et al. 2015).

Evaluación de las microestructuras espermáticas por Microscopia Electrónica de Barrido (MEB)

La MEB es una herramienta poderosa, que permite la observación y la caracterización de materiales orgánicos e inorgánicos heterogéneos y superficies a escala local. El área examinada o el microvolumen analizado es irradiado con un fino haz de electrones focalizados, el cual puede ser estático o mediante un barrido a través de la superficie del espécimen. Con la ayuda de esta herramienta, gran número de estudios sobre la fisiología espermática, han sido desarrollados en peces (Xin et al. 2014). En general, los espermatozoides de los peces, se han diferenciado en tres partes mayores por medio de la MEB: cabeza, pieza media y flagelo (Alavi et al. 2009; López-Hernández, 2017; Osorio-Pérez, 2017; Rurangwa et al. 2004).
El conocimiento sobre los espermatozoides en peces, ha incrementado considerablemente desde décadas pasadas. Dichos estudios se han enfocado en las diferencias morfológicas y estructurales entre especies, las cuales sirven como criterio para estudios evolutivos y taxonómicos (López-Hernández, 2017; Osorio-Pérez, 2017; Psenicka et al. 2007; Yasui et al. 2009). Además, el análisis por Microscopia Electrónica de Barrido provee información detallada sobre la ultraestructura subcelular espermática, y esto permite entender la morfología normal de los espermatozoides, la cual es valiosa en el desarrollo de métodos de criopreservación y la evaluación de posible daño celular, por la exposición hacia algún agente contaminante previo a procesos de fertilización artificial (Xin et al. 2014). El surgimiento de análisis por computadoras (AAME y CASA) en combinación con el análisis espermático por MEB, proveen de una opción versátil para el reemplazamiento de las técnicas de microscopia tradicional, por su fácil operación y objetividad durante el análisis de la velocidad de desplazamiento espermático, del tipo de movimiento y del tiempo de motilidad. Sin embargo, la adquisición de tales programas y equipos son altamente costosos. 
Evaluación de las microestructuras espermáticas por Microscopia Electrónica de Transmisión (MET)

El estudio de la ultraestructura espermática por MET de los diferentes grupos de peces, ha sido un tema popular desde décadas pasadas, debido principalmente a sus diferencias morfológicas específicas que reflejan variación en capacidades funcionales y filogenéticas entre especies (López-Hernández, 2017; Psenicka et al. 2008). El estudio ultraestructural de los espermatozoides de muchas especies de peces, ha mostrado que la organización de los orgánulos espermáticos es muy conservativa en miembros de la misma familia o subfamilia (Quagio-Grassiotto \& Oliveira, 2008). Sin embargo, en los teleósteos es muy difícil correlacionar filogenéticamente la ultraestructura espermática con modelos taxonómicos, ya que los espermatozoides de este grupo muestran gran variedad de tipos y formas incluso dentro de la misma familia sistemática. Los análisis por MET, han permitido describir de manera más detallada el proceso de espermatogénesis en un gran número de peces, y en las que características únicas han sido observadas, entre especies, así como correlaciones filogenéticas con otros grupos taxonómicos. En Siluriformes, las características morfológicas espermáticas son exclusivas del orden en comparación a otros grupos de teleósteos (López-Hernández, 2017; Qua-
gio-Grassiotto \& Oliveira, 2008). En algunas familias como Pimelodidae, Doradidae y Heptapteridae por ejemplo, un tipo especial de espermatogénesis ha sido caracterizado por MET, lo cual no es compartido con ningún otro orden (Quagio-Grassiotto \& Oliveira, 2008). El análisis de la morfología y ultraestructura espermática por MET, ha sido también empleado para la evaluación de la fertilidad en peces, cuando son expuestos a algún agente químico o manipulados para bancos de genoma mediante criopreservación.

\section{Parámetros químicos, bioquímicos y} lipídicos del plasma seminal

En la mayoría de los peces la espermatogénesis es de tipo quística y los espermatozoides son liberados dentro del sistema de ductos eferentes en el testículo, donde son sujetos a la fase de maduración al final de la espermatogénesis, o llamada espermiogénesis o espermiación (Schulz et al. 2010). Durante esta fase, el epitelio testicular produce el plasma seminal, como un fluido de componentes bioquímicos múltiples que rodean a los espermatozoides (Linhart et al. 2003). El papel principal del plasma seminal, es crear un medio óptimo para almacenar los espermatozoides, y también evitar la activación que mantiene el metabolismo que preserva la viabilidad y la energía para activar la motilidad (Linhart et al. 2003). Además de la morfología celular, la densidad, el volumen, la motilidad, la capacidad 
de fertilización, la osmolaridad y la composición del plasma seminal, han sido los parámetros más empleados para medir la calidad espermática en peces (Duan et al.2016). En la mayoría de los peces teleósteos, los espermatozoides están inactivos en el plasma seminal en los testículos. Factores como la osmolaridad en ciprínidos, la presión osmótica, la concentración de $\mathrm{K}^{+}$, la concentración de glucosa y el $\mathrm{pH}$ del plasma seminal $\geq$ a 7.0 en Salmónidos (Linhart et al. 2003; Tabares et al. 2005; Taati et al. 2010) y proteínas específicas del plasma seminal (Dumorné et al. 2017) con $120 \mathrm{kDa}$ en cíclidos, son factores que inhiben la motilidad espermática en peces dulceacuícolas (Linhart et al. 2003; Tabares et al. 2005; Taati et al. 2010).

En los peces, variaciones de parámetros químicos, bioquímicos $\mathrm{y}$ lipídicos se presentan en la misma familia y especies (Duan et al. 2016). Tales variaciones se encuentran asociadas principalmente, a los procesos de reproducción anual, o en ciclos reproductivos a lo largo del año (Linhart et al. 2003; López-Hernández, 2017; Osorio-Pérez, 2017). El conocimiento de los componentes del plasma seminal en peces, ha sido empleado para el desarrollo de Soluciones Reguladoras de la Vitalidad Espermática (SRVE) (Arias-Rodriguez, 2001), las cuales permiten la manipulación de los gametos con fines de reproducción artificial, manipulación cromosómica o criopre- servación (Duan et al. 2016; Linhart et al. 2003; Psenicka et al. 2008). En la acuicultura, el adecuado conocimiento de las características químicas y físicas del semen, permite el control y la producción exitosa de larvas en los sistemas de cultivo (Duan et al. 2016; Murakami et al. 2014).

\section{CONCLUSIONES Y PERSPECTIVAS}

En peces, como en la mayoría de los organismos con reproducción sexual, los espermatozoides tienen dos funciones importantes: activar la mayoría de los procesos moleculares del óvulo fertilizado y transmitir el material genético. En los machos, el éxito reproductivo depende de varios factores, entre ellos, la calidad del agua, la alimentación, la condición genética y la fisiología/capacidad reproductiva de las células espermáticas, para fertilizar el óvulo. La activación de las células espermáticas se lleva a cabo desde el momento en que el espermatozoide entra en contacto con el medio acuoso y los receptores de la membrana plasmática activan el movimiento flagelar. Los factores principales que intervienen durante la motilidad espermática son la presión osmótica, la composición iónica, el contenido de ATP y el $\mathrm{pH}$ en relación con el medio en el que habita el pez. Los espermatozoides maduros y funcionales son células haploides constituidas por una cabeza, una pieza media y un flagelo, todas ellas 
con morfología regular y acorde con las particularidades de cada especie que muestran variabilidad en forma, tamaño, número, localización de organelos y estructuras para la fertilización, como el flagelo y acrosoma en algunas especies; la observación de tales estructuras con herramientas de microscopia óptica, electrónica y por citometría automática, son necesarias para incrementar y optimizar los porcentajes de fertilización, sobre todo de especies en riesgo crítico de extinción y con importancia económica. Las estructuras que componen al espermatozoide deben tener buenas condiciones de simetría y funcionalidad, pues regulan el tiempo que una célula espermática se mueve (generalmente expresado en segundos), el tipo de motilidad de los espermatozoides o patrón de movimiento y el número de células activadas (porcentajes de motilidad). Lo anterior, es fundamental para garantizar porcentajes apropiados de fertilización, por ello es definida como calidad de los espermatozoides o calidad espermática. El conocimiento de la fisiología reproductiva de las células espermáticas, es importante como alternativa que favorece los programas de repoblación y de cruzas selectivas a través de fertilización artificial. El conocimiento de las bases fisiológicas de los espermatozoides es fundamental para programas de conservación temporal y criopreservación, necesarios para la creación de bancos de germoplasma. Los avances biotecnológicos con miras al empleo y a la manipulación de los gametos con amplios estándares de calidad fisiológica y genética, permitirán en el futuro, el aislamiento y la transferencia de núcleos apropiados para la creación selectiva de variedades híbridas con fines acuícolas, biológicos y experimentales. Aunado a que las herramientas genómicas, consentirán relacionar la calidad y el desempeño fisiológico con la expresión genética de células espermáticas individuales, que darán cabida a una mayor comprensión de la segregación y la herencia ligada a la eclosión, la sobrevivencia, la resistencia a enfermedades, el arribo a la primera alimentación, el desempeño de larvas, juveniles y adultos en los cultivos y el medio natural.

\section{BIBLIOGRAFÍA}

Aas, G. H., Refstie, T. \& Gjerde, B. (1991). Evaluation of milt quality of Atlantic salmon. Aquaculture, 95, 125-132. https://doi.org/10.1016/0044-8486(91)90079-M.

Aksoy, E., Aktan, T. M., Duman, S. \& Cuce, G. (2012). Assessment of spermatozoa morphology under light microscopy with different histology stains and comparison of morphometric measurements. Int. J. Morphol, 30(4), 1544-1550. https://doi.org/10.4067/ S0717-95022012000400045.

Alavi, S. M. H., Rodina, M., Viveiros, A. T. M., Cosson, J., Gela, D., Boryshpolets, S. \& Linhart, O. (2009). Effects of osmolality on sperm morphology, motility and flagelar wave parameters in Northern pike (Esox lucius L.). Theriogenology, 
72, 32-43. https://doi.org/10.1016/j. theriogenology.2009.01.015.

Arias-Rodriguez, L. (2001). Inactivación genética de esperma e inducción de ginogénesis y de triploidia en el botete diana Sphoeroides annulatus, (Jenyns, 1842). Tesis de maestría no publicada, Centro de Investigación para la Alimentación y Desarrollo, A. C. (CIAD), Unidad Mazatlán, Sinaloa, México.

Arias-Rodriguez, L., Rodríguez, I. L. E. \& Pignataro, V. G. (2004). Efecto de la radiación UV en la inactivación genética del esperma de botete diana Sphoeroides annulatus (Jenyns, 1842). Ciencias Marinas, 30, 390-402. https://doi. org/10.7773/cm.v30i3.334.

Arias-Rodriguez, L., Yasui, G. J., Kusuda, S., Fujimoto, K. \& Arai, K. (2010). Reproductive and genetic capacity of spermatozoa of inter-populational hybrid males in the loach, Misgurnus anguillicaudatus. J. Appl. Ichthyol, 26, 653658. https://doi.org/10.1111/j.14390426.2010.01534.x.

Álvarez, B., Arenal, A., Fuentes, R., Pimentel, R., Abad, Z. \& Pimentel, E. (2009). Methods in reproductive aquaculture: Marine and Freshwater Species. In E. Cabrita., V. Robles \& P. Herraez (Eds.), Use of post-thaw silver carp (Hypophtalmichthys molitrix) spermatozoa to increase hatchery productions (pp. 345-350). Florida, EE. UU.: C. R. C. Press.

Billard, R. (1986). Spermatogenesis and spermatology of some teleost fish species. Reprod. Nutr. Dévelop., 26(4), 877-920. https://doi.org/10.1051/rnd:19860601.

Billard, R., Cosson, J., Crim, L. W. \& Suquet, M. (1995a). Broodstock managament and egg and larval quality. In N. R. Bromage \& R. J. Robert (Eds.), Sperm physiology and quality (pp. 25-53). Boston, EE. UU.: Blackwell Science, Oxford.
Billard, R., Cosson, J., Perchec, G. \& Linhart, O. (1995b). Biology of sperm and artificial reproduction in carp. Aquaculture, 129, 95-112. https://doi. org/10.1016/0044-8486(94)00231-C.

Birkhead, T. R., Hosken, D. J. \& Pitnick, S. (2009). Sperm biology: An evolutionary perspective. Burlington, EE. UU.: ELSEVIER.

Bobe, J. \& Labbé, C. (2010). Egg and sperm quality in fish. General and Comparative Endocrinology, 165(3), 535548. https://doi.org/10.1016/j.ygcen.2009.02.011.

Brana, C., Benham, C. \& Sundstrom, L. (2002). A method for characterizing cell death "in vitro" by combining propidium iodide staining with immunohistochemistry. Brain Res. Protocols, 10(2), 109-114. https://doi. org/10.1016/S1385-299X(02)00201-5.

Cabrita, E., Martínez-Páramo, S., Gavaia, P. J., Riesco, M. F., Valcarce, D. G., Sarasquete, C., Herráez, M. P. \& Robles, V. (2014). Factors enhancing fish sperm quality and emerging tools for sperm analysis. Aquaculture. 432, 389401. https://doi.org/10.1016/j.aquaculture.2014.04.034.

Chalah, T. \& Brillard, J. P. (1998). Comparison of assessment of fowl sperm viability by eosin-nigrosin and dual fluorescence (SYBR-14/PI). Theriogenology, 50(3), 487-493. https://doi.org/10.1016/ S0093-691X(98)00155-1.

Chan, L. L., Wilkinson, A. R., Paradis, B. D. \& Lai, N. (2012). Rapid image-based cytometry for comparison of fluorescent viability staining methods. J. Fluores., 22(5), 1301-1311. https://doi. org/10.1007/s10895-012-1072-y.

Chapman, G. V. (2000). Instrumentation for flow cytometry. J. Immunol. Methods, 243(1), 3-12. https://doi.org/10.1016/ S0022-1759(00)00224-6. 
Ciereszko, A., Dietrich, M. A. \& Nynca, J. (2017). Fish semen proteomics - New opportunities in fish reproductive research. Aquaculture, 472, 81-92. https://doi.org/10.1016/j.aquaculture.2016.03.005.

Ciereszko, A., Wolfe, T. D. \& Dabrowskia, K. (2005). Analysis of DNA damage in sea lamprey (Petromyzon marinus) spermatozoa by UV, hydrogen peroxide, and the toxicant bisazir. Aquat. Toxicol., 73, 128-138. https://doi.org/10.1016/j.aquatox.2005.03.003.

Cosson, J., Groison, A. L., Suquet, M. \& Fauvel, C. (2008). Motility characteristics of spermatozoa in cod (Gadus morhua) and hake (Merluccius merluccius). Cybium, 32, 176-177.

Costache, M., Radu, D., Nicolae, C. G. \& Grosu, H. (2012). Relationships between morphology, motility and fertilization capacity in paddlefish (Polyodon spathula) spermatozoa. Adv. Res. Sci. Areas, 24(4), 1427-1429. https://doi.org/10.1111/j.1439-0426.2008.01145.x.

Coward, K., Bromage, N. R., Hibbitt, O. \& Parrington, J. (2002). Gamete physiology, fertilization and egg activation in teleost fish. Rev. Fish Biol. Fish., 12, 33-58. https://doi.org/10.1023/A:1022613404123.

Dreanno, C., Suquet, M., Desbruyeres, E., Cosson, J., Delliou, H. L. \& Billard, R. (1998). Effect of urine on semen quality in turbot (Psetta maxima). Aquaculture, 169, 247-262. https://doi. org/10.1016/S0044-8486(98)00262-2.

Duan, W., Xu, K., Hu, F., Zhang, Y., Wen, M., Wang, J., Tao, M., Luo, K., Zhao, R., Qin, Q., Zhang, C., Liu, J., Liu, Y. \& Liu, S. (2016). Comparative proteomic, physiological, morphological, and biochemical analyses reveal the characteristics of the diploid sper- matozoa of allotetraploid hybrids of red crucian carp (Carassius auratus) and common carp (Cyprinus carpio). Biology of Reproduction, 94, (1-2)35, 1-12. https://doi.org/10.1095/biolreprod.115.132787.

Dumorné, K., Figueroa, E., Cosson, J., Lee-Estevez, M., Ulloa-Rodríguez, P., Valdebenito, I. \& Farías, J. C. (2017). Protein phosphorylation and ions effects on salmonid sperm motility activation, Rev. Aquaculture, 0, 1-11. https://doi. org/10.1111/raq.12198.

Dziewulska, K., Rzemieniecki, A., Baranowska-Bosiacka, I., Domagała, J. \& Chlubek, D. (2012). The parameters of energetic status of the wild Atlantic salmon (Salmo salar L.) spermatozoa. Aquaculture Res., 43(1), 139-148. https://doi.org/10.1111/ j.1365-2109.2011.02833.x.

Dzyuba, B., Bondarenko, O., Fedorov, P., Gazo, I., Prokopchuk, G. \& Cosson, J. (2017). Energetics of fish spermatozoa: The proven and the possible. Aquaculture, 472, 60-72. https://doi.org/10.1016/j.aquaculture.2016.05.038.

Dzyuba, V. \& Cosson, J. (2014). Motility of fish spermatozoa: from external signaling to flagella response. Reprod. Biol., 14 (3), 165-175. https://doi.org/10.1016/j.repbio.2013.12.005.

Esteso, M. C., Rodríguez, E., Toledano-Díaz, A., Castaño, C., Pradiee, J., López-Sebastián, A. \& Santiago-Moreno, J. (2015). Descriptive analysis of sperm head morphometry in Iberian ibex (Capra pyrenaica): Optimum sampling procedure and staining methods using Sperm-Class Analyzer ${ }^{\circledR}$. Anim. Reprod. Sci., 155, 42-49. https://doi. org/10.1016/j.anireprosci.2015.01.014.

Fauvel, C., Suquet, M. \& Cosson, J. (2010). Evaluation of fish sperm quality. 
J. Appl. Ichthyol., 26(5), 636-643. https://doi.org/10.1111/j.14390426.2010.01529.x.

Fribourgh, J. H. (1966). The application of a differential staining method to low-temperature studies on goldfish spermatozoa. The Prog. Fish-Culturist, 28(4), 227-231. https://doi.org/10.1577/1548-8640(1966)28[227:TAOADS]2.0.CO;2.

Glogowski, J., M. Kwasnik., B. Piros., K. Dabrowski., K. Goryczko., S. Dobosz., H. Kuzminski \& A. Cierezko. (2000). Characterization of rainbow trout milt collected with a catheter: semen parameters and cryopreservation success. Aquaculture Res., 31, 289296. https://doi.org/10.1046/j.13652109.2000.00400.x.

Graham, J. K. (2001). Assessment of sperm quality: a flow cytometric approach. Anim. Reprod. Sci., 68, 239-247. https://doi.org/10.1016/S03784320(01)00160-9.

Herráez, M. P., Ausió, J., Devaux, A., González-Rojo, S., Fernández-Díez, C., Bony, S., Saperas, N. \& Robles, V. (2017). Paternal contribution to development: Sperm genetic damage and repair in fish. Aquaculture, 472, 45-59. https://doi.org/10.1016/j.aquaculture.2016.03.007.

Islam, M. S. \& Akhter, T. (2011). Tale of fish sperm and factors affecting sperm motility: A Review. Adv. Life Sci., 1, 11-19. https://doi.org/10.5923/j. als.20110101.03.

Jamieson, B. G. M. (1991). Fish evolution and systematics: evidence from spermatozoa. With a survey of lophophorate, echinoderm and protochordate sperm and an account of gamete cryopreservation. New York, USA: Cambridge University Press.
Jiménez-Trinidad, A. (2016). La osmolaridad y sus efectos en la vitalidad espermática del bagre tropical Rhamdia laticauda (Pisces: Heptapteridae). Tesis de Licenciatura no publicada, Universidad Juárez Autónoma de Tabasco, Villahermosa, Tabasco, México.

Koopman, G., Reutelingsperger, C. P. M., Kuijten, G. A. M., Keehnen, R. M. J., Pals, S. T. \& Vans Oers, M. H. J. (1994). Annexin $\mathrm{V}$ for flow cytometric detection of phosphatidylserine expression on B cells undergoing apoptosis. Blood, 84(5), 1415-1420.

Lahnsteiner, F. \& Patzner, R. A. (1998). Sperm motility of the marine teleosts Boops boops, Diplodus sargus, Mullus barbatus and Trachurus mediterraneus. J. Fish Biol., 52, 726-742. https:// doi.org/10.1111/j.1095-8649.1998. tb00816.x.

Lahnsteiner, F., Berger, B., Weismann, T. \& Patzner, R. A. (1998). Determination of semen quality of the rainbow trout, Oncorhynchus mykiss, by sperm motility, seminal plasma parameters, and spermatozoa metabolism. Aquaculture, 163, 163-181. https://doi.org/10.1016/ S0044-8486(98)00243-9.

Linhart, O., Cosson, J., Mims, S., Rodina M., Gela, D. \& Shelton, W. L. (2003). Effects of ions on the motility of fresh and demembranate spermatozoa of common carp (Cyprinus carpio) and paddlefish (Polyodon spathula). Fish Physiol. Biochem., 28(1-4), 203-5. https://doi.org/10.1023/B:FISH.0000030528.03098.6d.

López-Hernández, J. C. (2013). Efecto de la luz ultravioleta sobre la calidad espermática del juil tropical Rhamdia laticauda (Pisces: Heptapteridae). Tesis de Licenciatura no publicada, Universidad Juárez Autónoma de Tabasco, Villahermosa, Tabasco, México. 
López-Hernández, J. C. (2017). Biología, fisiología espermática básica y efecto de la radiación ultravioleta sobre la fisiología e integridad de las células espermáticas del bagre tropical Rhamdia laticauda. Tesis de Maestría no publicada, Universidad Juárez Autónoma de Tabasco, Villahermosa, Tabasco, México.

Mattei, X., Siau, Y., Thiaw, O. T. \& Thain, D. (1993). Peculiarities in the organization of testis Ophidion sp. (Pisces Teleosts). Evidence for two types of spermatogenesis in teleost fish. $J$. Fish. Biol., 43(6), 931-937. https:// doi.org/10.1111/j.1095-8649.1993. tb01167.x.

Menkveld, R. \& Kruger, T. E. (1996). Human Spermatozoa in Assisted Reproduction. In A. A. Acosta \& T. F. Kruger (Eds.), Basic semen analysis (pp. 53-72). New York, EE. UU.: Parthenon Publishing Group.

Miliorini, A. B., Murgas, L. D. S., Rosa, P. V., Oberlender, G., Pereira, G. J. M. \& da Costa, D. V. (2011). A morphological classification proposal for curimba (Prochilodus lineatus) sperm damages after cryopreservation. Aquaculture Res., 42(2), 177-187. https://doi.or$\mathrm{g} / 10.1111 / \mathrm{j} .1365-2109.2010 .02575 . x$.

Murakami, E., Rodrigueiro, R. J. B., Santos, T. C., Ospina-Rojas, I. C. \& Rademacher, M. (2014). Effects of dietary supplementation of meat-type quail breeders with guanidinoacetic acid on their reproductive parameters and progeny performance. Poult. Sci., 93(9), 22372244. https://doi.org/10.3382/ps.201403894.

Mylonas, C. C., Duncan, N. J. \& Asturiano, J. F. (2017). Hormonal manipulations for the enhancement of sperm production in cultured fish and evaluation of sperm quality. Aquaculture, 472, 21-
44. https://doi.org/10.1016/j.aquaculture.2016.04.021.

Mylonas, C. C., Fostier, A. \& Zanuy, S. (2010). Broodstock management and hormonal manipulations of reproduction. Gen. Comp. Endoc., 165(3), 516-534. https://doi.org/10.1016/j.ygcen.2009.03.007.

Osorio-Pérez, A. (2017). Fisiología y microestructura espermática del pejelagarto tropical Atractosteus tropicus. Tesis de Licenciatura no publicada, Universidad Juárez Autónoma de Tabasco, Villahermosa, Tabasco, México.

Patzner, R. A. (2008). Reproductive strategies of fish. In M. R. Rocha., A. Arukwe \& B. G. Kapoor (Eds.), Fish reproduction (pp. 311-351). New Hampshire, EE. UU.: Science Publishers.

Perchec, G., Jeulin, C., Cosson, J., André, F. \& Billard, R. (1995). Relationship between sperm ATP content and motility of carp spermatozoa. J. Cell Sci., 108, 747-753.

Psenicka, M., Alavi, S. M. H., Rodina, M., Cicova, Z., Gela, D., Cosson, J., Nebesarova, J. \& Linhart, O. (2008). Morphology, chemical contents and physiology of chondrostean fish sperm: a comparative study between Siberian sturgeon (Acipenser baerii) and sterlet (Acipenser ruthenus). J. Appl. Ichthyol, 24(4), 371-377. https://doi.org/10.1111/j.1439-0426.2008.01139.x.

Psenicka, M., Alavi, S. M. H., Rodina, M., Gela, D., Nebesarova, J. \& Linhart, O. (2007). Morphology and ultrastructure of Siberian sturgeon (Acipenser baerii) spermatozoa using scanning and transmission electron microscopy. Biol. Cell., 99(2), 103-115. https://doi. org/10.1042/BC20060060.

Quagio-Grassiotto, I. \& Oliveira, C. (2008). Sperm ultrastructure and a new type of spermiogenesis in two species of 
Pimelodidae, with a comparative review of sperm ultrastructure in Silurifomes (Teleostei: Ostaríophysis). Zool. Anz., 247(1), 55-66. https://doi. org/10.1016/j.jcz.2007.07.002.

Rakitin, A., Ferguson, M. M. \& Trippel, E. A. (1999). Spermatocrit and spermatozoa density in Atlantic cod (Godus morhua): correlation and variation during the spawning season. Aquaculture, 170(3-4), 343-358. https://doi. org/10.1016/S0044-8486(98)00417-7.

Rodríguez-Gutiérrez, M. (1992). Técnicas de evaluación cuantitativa de la madurez gonádica de peces. México: A. G. T. Editor.

Rurangwa, E., Kime, D. E., Ollevier, F. \& Nash, J. P. (2004). The measurement of sperm motility and factors affecting sperm quality in cultured fish. Aquaculture, 234(1-4), 1-28. https://doi.org/10.1016/j.aquaculture.2003.12.006.

Satterfield, J. R. \& Flickinger, S. A. (1995). Factors influencing storage potencial of preserved walleye semen. Prog. Fish Cult., 57(3), 175-181. https://doi. org/10.1577/1548-8640(1995)057 $<0175$ :FISPOP $>2.3$.CO;2.

Saudrais, C., Fierville, F., Loir, M., Le Rumeur, E., Cibert, C. \& Cosson, J. (1998), The use of phosphocreatine plus ADP as energy source for motility of membrane-deprived trout spermatozoa. Cell Motil. Cytoskel., 41(2), 91-106. https://doi.org/10.1002/(SICI)1097-0169(1998)41:2<91::AIDCM1 >3.0.CO;2-I.

Schreck, C. B. \& Moyle, P. B. (1990). Methods for Fish Biology. Maryland, EE. UU.: American Fisheries Society.

Schulz, R. W., França, L. R., Lareyre, J. J., LeGac, F., Chiarini-Garcia, H., Nobrega, R. H. \& Miura, T. (2010). Spermatogenesis in fish. Gen. Comp.
Endocr., 165(3), 390-411. https://doi. org/10.1016/j.ygcen.2009.02.013.

Schutte, B., Nuydens, R., Geerts, H. \& Ramaekers, F. (1998). Annexin V binding assay as a tool to measure apoptosis in differentiated neuronal cells. J. Neurosci. Methods, 86(1), 63-69. https://doi. org/10.1016/S0165-0270(98)00147-2.

Serafini, R., Longobardi, V., Spadetta, M., Neri, D., Aríota, B., Gasparrini, B. \& Di Palo, R. (2014). Trypan blue/giemsa staining to assess sperm membrane integrity in Salernitano stallions and its relationship to pregnancy rates. Reprod. Dom. Anim., 49(1), 41-47. https://doi.org/10.1111/rda.12221.

Taati, M. M., Mehrad, B., Shabani, A. \& Golpour, A. (2010). Correlation between chemical composition of seminal plasma and sperm motility characteristics of Prussian carp (Carassius gibelio). Int. J. Bioflux Soc., 3(3), 233-238.

Tabares, C. J., Tarazona, A. M. \& Olivera-Ángel, M. (2005). Fisiología de la activación del espermatozoide en peces de agua dulce. Rev. Colomb. Cienc. Pec., 18(2), 149-161.

van der Horst, G. \& Maree, L. (2010). Sperm

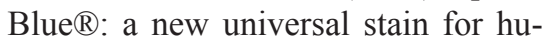
man and animal sperm which is also amenable to automated sperm morphology analysis. Biotech. Histochem., 84(6), 299-308. http://dx.doi. org/10.3109/10520290902984274.

Vermes, I., Haanen, C. \& Reutelingsperger, C. (2000). Flow cytometry of apoptotic cell death. J. Immunol. Methods, 243(12), 167-190. https://doi.org/10.1016/ S0022-1759(00)00233-7.

Wootton, R. J. \& Carl, S. (2014). Reproductive Biology of Teleost Fishes. In R. J. Wootton \& C. Smith (Eds.), Gametogenesis (pp. 45-80). Chichester, England: John Wiley \& Sons, Ltd. 
Wootton, R. J. \& Smith, C. (2014a). Reproductive Biology of Teleost Fishes. In R. J. Wootton \& C. Smith (Eds.). Mating systems and sexual selection (pp 201-249). Chichester, England: John Wiley \& Sons, Ltd. https://doi. org/10.1002/9781118891360.ch8.

Wootton, R. J. \& Smith, C. (2014b). Reproductive Biology of Teleost Fishes. In R. J. Wootton \& C. Smith (Eds.), Endocrinology of reproduction (pp. 81126). Chichester, England: John Wiley \& Sons, Ltd.

Xin, N., Liu, T., Zhao, H., Wang, Z., Liu, J., Zhang, Q. \& Qi, J. (2014). The impact of exogenous DNA on the structure of sperm of olive flounder (Paralichthys olivaceus). Anim. Reprod. Sci., 149,
305-310. https://doi.org/10.1016/j.anireprosci.2014.06.029.

Yasui, G. S., Arias-Rodriguez, L., Fujimoto, T. \& Arai, K. (2009). A sperm cryopreservation protocol for the loach Misgurnus anguillicaudatus and its applicability for other related species. Anim. Reprod. Sci., 116(3), 335-345. https://doi. org/10.1016/j.anireprosci.2009.02.021. Zhang, G., Gurtu, V., Kain, S. R. \& Yan, G. (1997). Early detection of apoptosis using a fluorescent conjugate of Annexin V. BioTechniques, 23(3), 525-531.

Zohar, Y. \& Mylonas, C. C. (2001). Endocrine manipulations of spawning in cultured fish: from hormones to genes. Aquaculture, 197(1-4), 99-136. https://doi. org/10.1016/S0044-8486(01)00584-1. 